\title{
mpulse Breakdown Strength of Nano-ZnO/XLPE Nanocomposite Material on Temperature Rise
}

\author{
Min-Hae Park, Kee-Joe Lim \\ Department of Electrical Engineering, Chungbuk National University, Cheongju, Republic of Korea \\ Email:minhaei@naver.com, kjlimg@gmail.com
}

Received 2012

\begin{abstract}
Development of new materials using composite materials has been much interest. XLPE is a kind of power cable in high voltage insulation. Recently research for cable insulating material has shown that nano-size filler added to XLPE is electrically and physically stable. In this paper, Impulse strength was measured in XLPE that composite by adding nano- $\mathrm{ZnO}$ with different mass proportions. There is positive and negative impulse voltage. However, there is no difference between them on the film specimen. Therefore we tested only positive voltage. In order to understand temperature properties of XLPE nanocomposite sample, experiment of impulse breakdown strength were measured at room temperature and maximum allowable temperature $\left(90^{\circ} \mathrm{C}\right)$. From this result, it can be considered that the breakdown strength of addition of the nano- $\mathrm{ZnO}$ is increased in a corresponding degree at high temperature, but almost unchanged at low temperature.
\end{abstract}

Keywords: XLPE; Nano Composite; Nano-ZnO; Impulse Breakdown Strength

\section{Introduction}

Studies that are involved in impulse breakdown for the DC insulation materials have plenty. Nevertheless, it is mostly the polymer insulation materials in low electric fields.

In this study, a nanocomposite material of nano-Zinc oxide $(\mathrm{ZnO})$ added to a cross linking-polyethylene (XLPE, used for high voltage cable insulation) was subjected to impulse property investigation. The purpose of this study is to investigate the electrical properties influence on temperature rise. In this paper, the experimental preparation of $\mathrm{ZnO} / \mathrm{XLPE}$ nanocomposite is described. And the impulse breakdown strength of $\mathrm{ZnO} / \mathrm{XLPE}$ is measured under quasi-uniform fields.

\section{Experiment}

\subsection{Specimens}

The details of nanocomposite sheet specimens containing different filler concentrations are included in Table 1. Silane treated nano-ZnO (Nanostructured and Amorphous Materials, Inc) with the diameter of 90-210nm was incorporated in XLPE. The samples were diluted to the prescribed concentration of 1,3 and $5 \mathrm{phr}$. And XLPE was also prepared as $0 \mathrm{phr}$ sample for comparison. The dispersion state of $\mathrm{ZnO}$ was estimated by using a transmission electron microscope (TEM) as shown in Table 2.
Table 1. Details of nanocomposite dielectrics

\begin{tabular}{ll}
\hline Base Polymer & XLPE \\
\hline Filler & Nano-ZnO \\
\hline Filler concentrations(phr) & $0,1,3$ and 5 \\
\hline Dielectric thicknesses & $100 \sim 150 \mu \mathrm{m}$ \\
\hline Surface treatment on filler & Silane treated \\
\hline Test temperatures & Room temperature, $90^{\circ} \mathrm{C}$ \\
\hline
\end{tabular}

Table 2. Dispersion state of Zinc Oxide

\begin{tabular}{|c|c|c|c|c|}
\hline & TEM & $\begin{array}{c}\text { Particle } \\
\text { size }\end{array}$ & Purity & $\begin{array}{c}\text { Mor- } \\
\text { phology }\end{array}$ \\
\hline $\mathrm{ZnO}$ & & $\begin{array}{c}90-210 \mathrm{n} \\
\mathrm{m}\end{array}$ & $99.9 \%+$ & Irregular \\
\hline
\end{tabular}

\subsection{Experimental Procedures}

In order to temperature dependence of XLPE nanocomposite sample, Impulse breakdown strength were measured at room temperature and maximum allowable temperature $\left(90^{\circ} \mathrm{C}\right)$. Samples were sandwiched between stainless steel sphere electrodes with a diameter of $8 \mathrm{~mm}$. The sample and electrodes were soaked in silicon oil because of avoiding breakdown in air. The experiments were done more than 10 times under each condition. The 
impulse breakdown test was performed at the wave front of the one shot impulse.

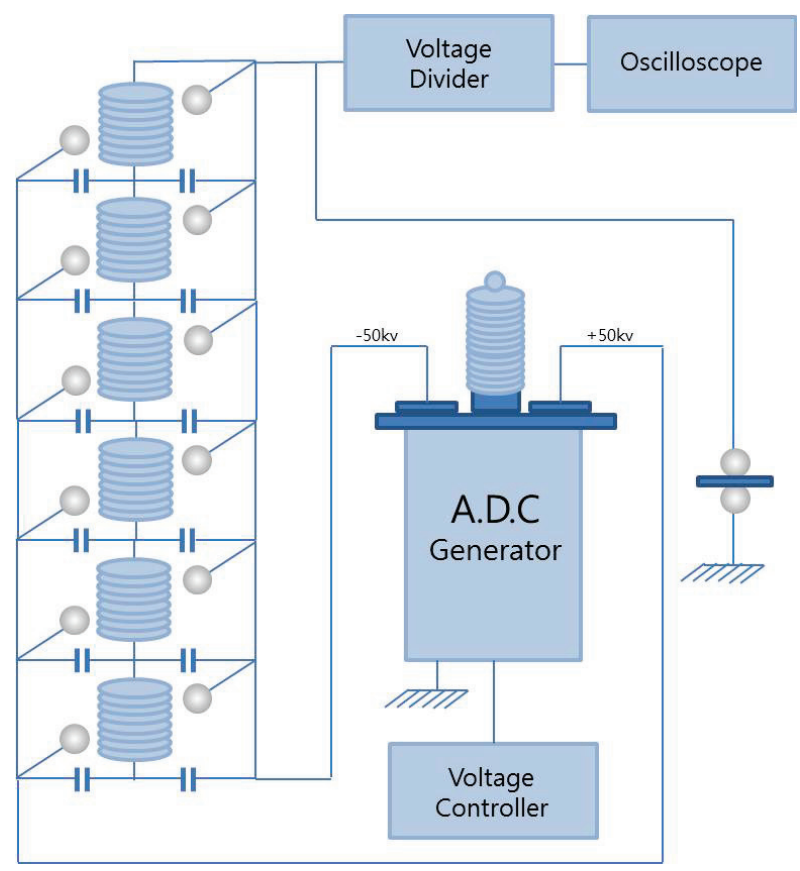

Figure 1. Experimental setup for Impulse breakdown test

\section{Results and Discussion}

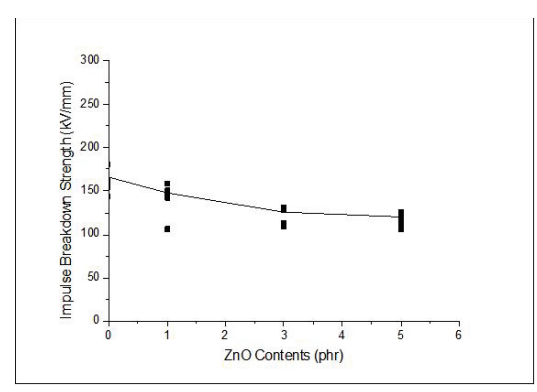

(a) Room temperature $\left(25^{\circ} \mathrm{C}\right)$

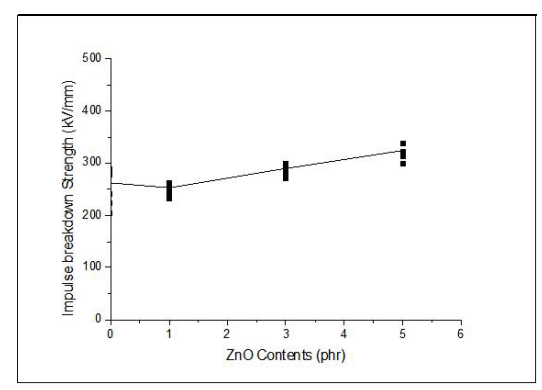

(b) High temperature $\left(90^{\circ} \mathrm{C}\right)$

Figure 2. ZnO content dependence of impulse breakdown strength of $\mathrm{ZnO} / \mathrm{XLPE}$ nanocomposite material

Figure 2 shows the influence of nano- $\mathrm{ZnO}$ on temperature rise using sphere-sphere electrode. The breakdown strength was calculated by dividing the breakdown voltage by the film thickness. The scatter and weibull scale parameter plot are appeared as dots and line.

Figure 2(a) shows that the impulse breakdown strength is similar to $\mathrm{ZnO}$ content of $3 \mathrm{phr}$ or more. By comparison, less than $3 \mathrm{phr}$ is decreased.

The impulse breakdown strength at 90 degrees Celsius is shown in Figure 2(b). The breakdown strength of Adding $\mathrm{ZnO}$ is higher than XLPE by observation.

The addition of a few $\mathrm{ZnO}$ nano-filler brought the improvement of the impulse breakdown strength at high temperature $\left(90^{\circ} \mathrm{C}\right)$. However, adding nano- $\mathrm{ZnO}$ couldn`t be huge exchange of XLPE.

\section{Conclusions}

We investigated impulse breakdown strength in XLPE and its composite by adding nano- $\mathrm{ZnO}$ with different mass proportions. The impulse breakdown strength of nanocomposite was measured with sphere-sphere electrode at room temperature and maximum allowable temperature $\left(90^{\circ} \mathrm{C}\right)$. In this study, specimens of addition of the nano-ZnO were similar to XLPE in impulse breakdown strength at room temperature, however, appeared excellent results at 90 degree Celsius. We considered that temperature dependent was relatively low. This means that the decrease in breakdown strength at high temperature is relatively small.

\section{REFERENCES}

S. Q. Chen, Z. R. Peng, X. Wang, M. B. Zheng, "Study on the Effect of Nano-ZnO as Photo Aging Stabilizer in LDPE Insulation", Proceedings of the $9^{\text {th }}$ International Conference on Properties and Applications of Dielectric Materials, Harbin, China, 19-23 July 2009, pp. 812-815\%\%\%Shunsuke Okuzumi, Yoshinobu Murakami, Masayuki Nagao, Yoitsu Sekiguchi, Ch. Chakradhar Reddy and Yoshinao Murata, "DC Breakdown Strength and Conduction Current of $\mathrm{MgO} / \mathrm{LDPE}$ Composite Influenced by Filler Size", 2008 Annual Report Conference on Electrical Insulation Dielectric Phenomena, 2008, pp. $722-725 \% \% \%$ Y. Murata, Y. Sekiguchi, Y. Inoue and M. Kanaoka, "In-vestigation of Electrical Phenomena of Inorgan-ic-filler/LDPE Nanocomposite Material”, ISEIM 2005, Vol.3, Kitakyushu, Japan, 5-9 June 2005, pp.650-653\%\%\%Yujie Hu, Robert C. Smith, J. Keith Nelson and Linda S. Schadler, "Some mechanistic understanding of the impulse strength of nanocomposites", 2006 Annual Report Conference on Electrical Insulation and Dielectric Phenomena, 2006, pp. 31-34 